\title{
Enquadramentos na medicina regenerativa: os relatos recentes na imprensa brasileira
}

\author{
Frames in regenerative medicine: recent news in the Brazilian press \\ Marcos referenciales de la medicina regenerativa: noticias recientes en la \\ prensa brasileña
}

\author{
Liliana Acero ${ }^{1, a}$ \\ lilianaacero2009@gmail.com | http://orcid.org/oooo-0002-5460-3363 \\ ${ }^{1}$ Universidade Federal do Rio de Janeiro, Instituto de Economia, Programa de Pós-graduação em Políticas Públicas, \\ Estratégias e Desenvolvimento. Rio de Janeiro, RJ, Brasil. \\ ${ }^{a}$ Doutorado em Sociologia pela University of Sussex.
}

\section{RESUMO}

A mídia funciona como uma ponte entre a medicina e o público, e impacta como a informação é organizada e apresentada às pessoas. Realizou-se uma análise de conteúdo, quantitativo e qualitativo, dos enquadramentos principais nas matérias sobre medicina regenerativa publicadas pela Folha de S.Paulo e O Globo, entre janeiro de 2012 e maio do 2019. A análise mostrou algumas limitações nas informações publicadas: um número bastante escasso de relatos, com poucas matérias sobre controvérsias sociais e regulatórias e matérias de tons otimistas demais sobre os benefícios das terapias celulares. Conclui-se que falta uma contribuição mais sistemática da imprensa à legitimação social e institucional desta área de ponta no país, desenvolvida com recursos públicos e que oferece uma oportunidade imperdível no aumento da consciência em saúde coletiva, assim como, na participação competitiva do Brasil no cenário global.

Palavras-chave: Medicina regenerativa; Terapia celular; Mídia; Saúde coletiva; Enquadramentos científicos; Cobertura midiática.

\section{ABSTRACT}

Mass media works as a bridge between medicine and the public and produces an impact according to how information is organized and presented. A quantitative and qualitative content analysis was developed on the main framings on regenerative medicine found in reports by the newspapers Folha de S.Paulo and 
O Globo between January 2012 and May 2019. The analysis found limitations in the information published: a reduced number of stories, the presence of few articles on social and regulatory controversies and a portrayal of over-optimistic accounts on the benefits of cellular-based therapies. The article concludes that there is a lack of a more systematic contribution of the printed press to the social and institutional legitimation of the local area, one developed with public resources and that offers a valuable opportunity to raise awareness on collective health, as well as, for a competitive inclusion of Brazil at the global level.

Keywords: Regenerative medicine; Cellular therapy; Mass media; Collective health; Scientific framings; Media coverage.

\section{RESUMEN}

Los medios de comunicación masiva funcionan como un puente entre la medicina y el público, e impactan en los públicos según cómo la información sea organizada y presentada. Se realizó un análisis de contenido, cuantitativo y cualitativo, de los encuadramientos principales en los diarios: Folha de S.Paulo y O Globo sobre la medicina regenerativa entre enero de 2012 y mayo de 2019. El análisis demostró las limitaciones de los contenidos: um número bastante escaso de reportajes, pocas noticias sobre debates y controversias sociales y de tono demasiado optimista acerca de los beneficios de las terapias celulares. Se concluye que falta una contribución sistemática de la prensa a la legitimación social e institucional de esta área de punta em el país, desarrollada com recursos públicos y que ofrece una valiosa oportunidad para un aumento de conciencia sobre la salud colectiva y una participación competitiva de Brazil en el escenario global.

Palabras clave: medicina regenerativa; terapia celular; medios de comunicación de masas; salud colectiva; encuadramientos científicos; cobertura mediática.

Contribuição dos autores:

Concepção e desenho do estudo: Liliana Acero.

Aquisição, análise ou interpretação dos dados: Liliana Acero.

Redação do manuscrito: Liliana Acero.

Revisão crítica do conteúdo intelectual: Liliana Acero.

Declaração de conflito de interesses: não há.

Fontes de financiamento: Programa de Pós-graduação em Políticas Públicas, Estratégias e Desenvolvimento (PPED), Instituto de Economia (IE), Universidade Federal do Rio de Janeiro (UFRJ).

Considerações éticas: aprovação do projeto de pesquisa geral pelo Comité de Ética em Pesquisa do Centro de Filosofia e Ciências Humanas da UFRJ (CFCH); 8/2019.

Agradecimentos/Contribuições adicionais: agradeço as Prof. Maria Tereza Leopardi e Ana Celia Castro, Coordenadora e Vicecoordenadora do Programa de Pós-graduação em Políticas Públicas, Estratégias e Desenvolvimento (PPED), Instituto de Economia (IE), Universidade Federal do Rio de Janeiro (UFRJ) pelo apoio a meu trabalho como Professora Visitante Senior Estrangeira e a orientanda de Doutorado do PPED, Bruna Castanheira pela coleta e sistematização inicial dos dados empíricos na base do artigo.

Histórico do artigo: submetido: 9 dez 2019 | aceito: 30 jun. 2020 | publicado: 17 dez. 2020.

Apresentação anterior: não houve.

Licença CC BY-NC atribuição não comercial. Com essa licença é permitido acessar, baixar (download), copiar, imprimir, compartilhar, reutilizar e distribuir os artigos, desde que para uso não comercial e com a citação da fonte, conferindo os devidos créditos de autoria e menção à Reciis. Nesses casos, nenhuma permissão é necessária por parte dos autores ou dos editores. 


\section{INTRODUÇÃO}

Os meios de comunicação de massa funcionam como uma ponte entre a ciência, a medicina e o público¹. Caracterizamos esses meios com base na definição anglófona de mídia como dispositivos comunicacionais que se produzem de vários modos e informam a população². Esses se diferenciam do conceito de 'mediação', de natureza culturalista, interconectam processos simultâneos de cultura e comunicação e aludem a recepção das mensagens ${ }^{3}$, como também do conceito de 'midiatização'. Esse conceito refere-se às formas e ao tecido da cultura e da sociedade que se satura por uma ação contínua das tecnologias e da informação moldada pela mídia, funcionando como paradigma dominante: um "epifenômeno da ecologia medial" (p. 61).

Porém, o efeito dessa informação nas opiniões dos indivíduos em relação à ciência/medicina depende, em grande medida, de como ela é organizada e apresentada às pessoas. Tem-se considerado que a cobertura da mídia também influencia a legitimação da ciência/medicina e contribui para o seu suporte público e financiamento ${ }^{3}$.

Recentemente, uma grande quantidade de instituições científicas está estabelecendo interfaces profissionais para atender às demandas midiáticas: uma nova 'midiatização' da ciência/medicina' ou um processo mútuo de reorientação entre a ciência e a mídia, para que as instituições obtenham: um aumento na sua legitimação, consciência dos agentes de políticas públicas sobre os temas de interesse dos cientistas/ médicos e uma ajuda no acesso ao financiamento 4 . Mas esse processo tem gerado também controvérsias, na medida em que o domínio de fontes institucionais na construção das notícias gera um viés a favor das agendas de grupos de interesses específicos.

Na última pesquisa governamental de percepção pública sobre a ciência e a tecnologia realizada em 2019 no Brasil ${ }^{5}$, evidenciou-se que o público consulta os jornais impressos: frequentemente $-3 \%$; às vezes $-16 \%$ e raramente ou nunca - 81\%; percentuais muito semelhantes aos que consultam os programas de rádio sobre esses assuntos (Tabela 1). Contudo, a informação em internet/redes sociais é a que aparece como mais consultada no total e de modo muito mais frequente do que as matérias nos jornais impressos. Os programas televisivos figuram em segundo lugar como os mais consultados pela população. Outros dados dessa enquete nacional não podem ser analisados, uma vez que a informação tem sido apenas parcialmente publicada.

Tabela 1 - Número de consultas em diferentes tipos de mídia pela população entrevistada na enquete nacional 2019, em \%

\begin{tabular}{lcccc}
\hline \multicolumn{1}{c}{ Tipo de Mídia } & Frequentemente & Às vezes & $\begin{array}{c}\text { Raramente ou } \\
\text { nunca }\end{array}$ & Base* \\
\hline Internet/Redes & 14 & 37 & 61 & 100 \\
Programas de TV & 11 & 25 & 52 & 100 \\
Jornais impressos & 3 & 16 & 81 & 100 \\
Programas de rádio & 3 & 15 & 81 & 100 \\
Base* & 100 & 100 & 100 & 100 \\
\hline
\end{tabular}

Fonte: Adaptado de Percepção pública da C\&T no Brasil (2019, p. 16)5.

*O gráfico original inclui outros meios de acesso à informação cientifica não incluídos nesta Tabela, ex. livros e revistas.

O presente artigo foi motivado pela intenção de compreender o impacto potencial das matérias jornalísticas na medicina regenerativa (MR) - que inclui as pesquisas com células-tronco (PCT) e as terapias celulares (TC) - sobre o entendimento público de setores sociais selecionados. Assim, foi considerado que o conteúdo analisado na imprensa atrai relativamente poucos leitores, possivelmente pertencentes a um grupo social de elite. Dessa forma, considera-se válida a exploração realizada, já que as características das matérias reportadas (p. ex. quantidade, qualidade e estilo) podem influir nas escassas consultas, além 
dos fatores socioeconômicos locais mais gerais. Este estudo faz parte de um trabalho mais abrangente e comparativo que está sendo realizado pela autora e que inclui pesquisa sobre a divulgação da MR brasileira em diferentes veículos midiáticos - aqueles mais e menos consultados pela população geral, quer dizer, mídia digital, televisiva e impressa. Para uma análise das notícias em MR na televisão e na impressa, consultar ${ }^{6-7}$.

O presente trabalho pretende analisar os conteúdos na imprensa em MR no Brasil, utilizando matérias de dois jornais nacionais de renome e ampla circulação: a Folha de S.Paulo e o Jornal O Globo. Aplicam-se na análise alguns conceitos da abordagem em Ciência, Tecnologia e Sociedade (CTS), com fins de responder às seguintes perguntas:

- Até que ponto e de que forma a imprensa selecionada no Brasil reporta evidência da medicina regenerativa?

- Quais são os enquadramentos principais nos quais podem ser classificadas as matérias?

- Quais são as principais valências, tons e fontes delas?

\section{O CONTEXTO DA REPORTAGEM DA CIÊNCIA NA IMPRENSA}

A área de estudos da comunicação pública da ciência tem recebido muito mais atenção nas últimas décadas em nível global - como será discutido a seguir. Uma meta-análise internacional de estudos sobre a cobertura midiática em ciência ${ }^{1}$ comprovou que entre os anos de 1960 e 2000 encontram-se alguns vieses: a publicação de uma maior quantidade de artigos dos países ocidentais - especialmente da Europa Ocidental, os EUA e a Oceania - sendo apenas 1,6\% dos estudos provenientes de países não ocidentais, e escassos os estudos sobre a África, a América do Sul e a Ásia.

No caso da América Latina, a situação reflete diversas características próprias. Nesse sentido, prevalecem os estudos quantitativos sobre informação científica em geral, que são inespecíficos em relação aos assuntos prioritários discutidos no presente artigo. Um diagnóstico recente sobre a divulgação pública de resultados científico/médicos na região reporta que estas comunicações são feitas principalmente por meio da mídia, ainda que existam algumas ações presenciais direcionadas a estudantes do ensino básico e médio ${ }^{8}$ desenvolvidas com recursos escassos e executadas por voluntários. Essas costumam promover visitas a museus, férias e conversas/conferências junto a cientistas/médicos.

Outro trabalho acadêmico quantificou os artigos que estudam a mídia científica publicados no período entre 2008 e 2017, em nível global, em três revistas acadêmicas especializadas e internacionalmente renomadas: Science Communication (SC), Public Understanding of Science (PUS) e Journal of Science Communication (JCOM). O estudo encontrou que em apenas 4\% de um total de 954 artigos há análise de casos empíricos de algum país ou grupos de países na América Latina ${ }^{9}$. Por contraste, e em conjunto, cinco países contribuem com 825 artigos, ou seja, 66,7\% do total, na seguinte ordem: os EUA, o Reino Unido, o Canadá e a Austrália. A frequência de publicações de América Latina manteve-se constante nos dez anos analisados e apresentou uma média de 4 a 5 artigos por ano.

Além disso, evidenciou-se que as publicações recentes de artigos de autores da América Latina sobre ciência na mídia ( $31 \%$ das atividades totais avaliadas em outro estudo) em 80 revistas internacionais concentram-se em estudos do Brasil, da Colômbia, da Argentina e do México ${ }^{10}$. Em segundo lugar, predominam os artigos sobre os museus de ciência e sobre a divulgação da ciência no ensino - como parte das estratégias de 'popularização da ciência e a tecnologia' adotadas por vários países na região. 


\section{A MÍDIA NA MEDICINA REGENERATIVA}

Os assuntos médicos de ponta - como, por exemplo, a medicina molecular - figuram entre os temas mais frequentemente presentes na cobertura midiática global ${ }^{11}$. Entretanto eles cobrem um amplo espectro de disciplinas científicas: as pesquisas com células tronco, a terapia gênica e o sequenciamento dos genes no genoma humano, tornando-se, às vezes, confusa a delimitação entre tipos de assuntos.

No caso do Brasil, não foi encontrado nenhum estudo publicado de tipo empírico - estudo setorial, estudo de caso ou outros tipos de análise qualitativa - da mídia na MR brasileira, segundo uma consulta breve no aplicativo google acadêmico e buscas nos arquivos do catálogo de teses e dissertações do Coordenação de Aperfeiçoamento de Pessoal de Nível Superior (Capes); da Plataforma Lattes do Conselho Nacional de Desenvolvimento Científico e Tecnológico (CNPq) e dos sítios web de algumas das revistas brasileiras centrais em saúde e ciência: Ciência e Saúde Coletiva, Physis - Revista de Saúde Coletiva, Tecnologia e Sociedade; História, Ciência e Saúde - Manguinhos e Revista Eletrônica de Comunicação, Informação \& Inovação em Saúde (Reciis). Foi localizado um total de quatro trabalhos de ciências sociais, a maioria dissertações de Mestrado e teses de Doutorado, - e além dos da autora - e que contemplam os seguintes assuntos: a) afirmações gerais sobre o papel da mídia na MR; b) um trabalho teórico sobre longevidade e envelhecimento; c) um estudo de bioética em Ciência e Tecnologia na televisão; e d) uma análise sobre técnicas em biotecnologias na imprensa.

Muitos outros trabalhos na mídia local e global focam em debates específicos na MR, como os da pesquisa com células tronco embrionárias (PCTE), a clonagem terapêutica e humana ${ }^{12}$, assim como o escândalo das pesquisas do professor Hwang da Coréia do $\mathrm{Sul}^{13}$. Os debates em PCTE têm sido analisados em trabalhos prévios da autora ${ }^{14-15} \mathrm{e}$, em outros específicos, a cobertura da mídia ${ }^{16-19}$.

Outros ensaios são apenas indiretamente relevantes à nossa pesquisa. Por exemplo, Leydesdorff; Hellsten $^{20}$ estudaram, para o ano 2001, os múltiplos sentidos em que se utiliza o termo células-tronco na pesquisa, nas aplicações e debates políticos nos jornais The New York Times e The Guardian, com base nos títulos e referências dos documentos. O trabalho expõe um mapa referencial muito geral. Já Marks e colaboradores ${ }^{21}$, em um estudo longitudinal dos marcos da biotecnologia nos EUA e no Reino Unido, mostra a existência de um viés a favor da reportagem das descobertas biomédicas versus as aplicações agrícolas da biotecnologia, o qual o autor explica - de modo bastante simplista - pelos interesses predominantes do público europeu na saúde. No estudo de Caulfield ${ }^{22}$, analisam-se os enquadramentos sobre biotecnologia na mídia e conclui-se que são altamente influenciados pelo meio ambiente cada vez mais comercial da pesquisa científica; um resultado a ser considerado - a meu ver - também no caso do presente estudo.

Entre os trabalhos mais relevantes ao presente artigo, nos referiremos com mais detalhe ao de Nisbet; Brossard; Kroepsch ${ }^{23}$, aos mais recentes de Kamenova; Caulfield ${ }^{24}$ e de Kamenova ${ }^{25}$ e, de modo tangencial, ao de Lynch e outros autores ${ }^{26}$. O primeiro oferece um panorama quantitativo da cobertura midiática da MR nas últimas quatro décadas e classifica a produção segundo estágios de desenvolvimento ligados a eventos importantes na área. Exploram-se as esferas políticas onde se desenvolvem as matérias, os níveis de drama nos textos apresentados e a utilização de analogias com histórias mais familiares ao público. O estudo realiza uma discussão aprofundada da influência dos momentos políticos - em especial nos EUA - nas agendas dos governos, na apresentação pública da MR e na dramaticidade das narrativas utilizadas; todas essas variáveis relevantes.

O estudo de Kamenova e Caulfield ${ }^{24}$ pesquisa a forma como a imprensa apresenta, entre 2010 e 2013, a nova fase translacional de resultados de pesquisa à clínica, um dos objetivos do presente trabalho. Analisa como se descrevem os períodos de tempo para a produção de terapias celulares (TC) e como se prognostica o futuro da área. Entre os resultados, os autores acharam que o retrato midiático da perspectiva do futuro, bastante semelhante entre EUA, Reino Unido e Canadá, é otimista em 57,7\% das matérias. Além 
disso, a maioria dos textos reportava um tempo de chegada das TC ao mercado de 5 a1o anos, ainda que uma proporção significativa as considerasse como disponíveis apenas em um futuro distante. A análise quantitativa/qualitativa comparativa entre países é abrangente e pioneira, e mostra, em especial, a indução de expectativas exageradas pela mídia em suas audiências e a desinformação em referência aos períodos e formas de aprovação das TC.

Os autores discutidos concluem que existe uma grande discrepância entre os reais desenvolvimentos científicos na MR e como estes são apresentados na mídia e percebidos pelo público. Por exemplo, um estudo de Bubela e colaboradores ${ }^{27}$ indica que, apesar dos ensaios clínicos na PCT se centrarem na doença de graft-versus-host e no tratamento do câncer, a cobertura midiática foca-se em aplicações sobre as condições neurológicas, cardiovasculares e a diabetes. Todos os autores enfatizam o domínio na imprensa das reportagens sobre ensaios clínicos em TC e a escassez de matérias associadas a questões éticas, legais e sociais. Achamos que esta situação tem um impacto altamente prejudicial sobre a capacidade de posicionamento das audiências nos diferentes aspectos controversos e irresolutos da MR, em especial, nos seus riscos e incertezas, além de interferir no entendimento/engajamento público e omitir qualquer reflexão da importância dos direitos dos cidadãos quanto à saúde.

Como uma das fontes principais das notícias provém da comunidade científica, infere-se que os cientistas têm oferecido aos jornalistas cenários irreais sobre os períodos de tempo para a aprovação das TC e, assim, têm contribuído para gerar falsas expectativas no público. Nessa linha, Kamenova ${ }^{25}$, analisando as notícias em PCTE em jornais do Canadá, EUA, Polônia, Reino Unido e França entre 1998 e 2013, explicou o papel ativo da mídia em validar principalmente as reivindicações científicas favoráveis às descobertas na MR, em vez de desconstruir os temas. A mídia tem reproduzido as discussões nas áreas políticas e legislativas e oferece uma escassa reflexão crítica sobre os exageros ('hypes') das descobertas. O texto desenvolve critérios úteis para a nossa pesquisa atual e referentes à utilização na mídia de diferentes modelos do entendimento/ engajamento público na ciência.

Tem se comprovado também na MR global que o uso frequente dos agentes de relações públicas e dos comunicados de imprensa tende a favorecer os interesses internos às comunidades científicas. Os jornalistas priorizam as histórias que se relacionam com aplicações técnicas e desenvolvem a sua própria interpretação favorável ${ }^{26}$.

\section{ABORDAGEM CONCEITUAL}

O presente artigo se fundamenta em duas abordagens teóricas principais e em interconexão: a aproximação dos enquadramentos (frames/framing analysis) e a configuração das agendas (agendasetting), que são utilizadas na análise de conteúdo das matérias selecionadas.

A aproximação sociológica de enquadramento inclui uma diversidade de perspectivas quantitativas e qualitativas, e tem um caráter interdisciplinar, com aportes dos seguintes campos: o cognitivo e o de estudos de desconstrução e crítica social ${ }^{28}$. O modelo de pesquisa atual em framing tem uma característica de ponte interdisciplinar multiparadigmática.

Começou sua utilização na psicologia social com o trabalho de Gregory Bateson; mas foi Erwin Goffman²9 o pioneiro na introdução da abordagem sociológica, que descreveu o frame/framing como: "schema of interpretation that allows people to locate, perceive, identify, and label a seemingly infinite number of concrete occurrences defined in its limits" (p. 21).

No campo de estudos da comunicação e do jornalismo, aspectos dos enquadramentos foram redefinidos, o que gerou o aumento do ecletismo das metodologias com essa base analítica. Em geral, adaptou-se o conceito operacional ao objeto estudado em cada caso, combinando-se às vezes, "a análise de enunciados linguísticos e contextos sociais ou 'mundos de referência' acionados no processo de construção da notícia”’30 (p.3). 
As organizações ligadas à mídia estão interessadas em especial nos efeitos que a comunicação produz com fins de otimizá-los. "News media are no doubt the most important actors in the framing process. They are frame generators, organizers, and transmitters, linking social structure and the individual. News content is not mere combinations of words; it carries embedded social meaning and reflects the prevalent organizing principles in society through journalists' selection of words, news sources, and metaphors. This process sets the boundary of an issue, reduces a complex situation to a simple theme, and shapes people's interpretations by making some elements salient while ignoring others" ${ }^{31}$ (p. 638).

Uma definição de enquadramento já bastante aceita é a desenvolvida por Entman ${ }^{32}$ : "To frame is to select some aspects of perceived reality and make them more salient in a communicating text, in such a way as to promote a particular problem definition, causal interpretation, moral evaluation, and/or treatment recommendation for the item described" (p.52).

Nos enquadramentos se salientam alguns aspectos da realidade, enquanto outros são relegados ou ocultados; selecionam-se e sugerem-se, assim, atributos, julgamentos e decisões dentro do relato para promover uma interpretação específica. Esta inclui uma inter-relação entre quatro elementos que promovem: uma definição particular do problema, uma interpretação causal, uma avaliação moral (teor dos julgamentos positivos e negativos, descrição dos riscos e benefícios) e uma solução, tratamento ou forma de remediar uma situação. E podem se localizar em, pelo menos, quatro lugares dentro do processo comunicacional: o comunicador, o texto, o receptor e a cultura. Um enquadramento é um trabalho organizativo e estruturante, ou seja, se constitui em mais de um tópico dentro de uma matéria.

Para melhorar a confiabilidade e validade das medidas dos enquadramentos, Matthes; Kohrin33 propuseram a medição de elementos separados dos frames que, depois de codificados, podem ser analisados em termos de padrões persistentes: "That means when some elements group together systematically in a specific way, they form a pattern that can be identified across several texts in a sample. We call these patterns frames"33 (p. 263). Os elementos codificados dentro da análise de conteúdo são tipificados com características relevantes, p. ex.: uma categoria que mede diferentes tipos de incerteza científica ${ }^{34}$.

No caso do Brasil, um levantamento dos trabalhos locais que utilizam o conceito de enquadramento noticioso entre 2013-2016 encontrou 19 trabalhos realizados em relação à imprensa. Houve escassas referências às mudanças nas visões de mundo refletidas nesses veículos emergentes, que podem ressignificar a forma de utilizar o próprio conceito de enquadramento. Além disso, nenhum dos estudos é centrado em assuntos da ciência e da saúde e, ainda menos, da MR. A maioria aborda temas de ordem política e da participação democrática ${ }^{30}$.

A visão central da abordagem de configuração de agenda (agenda-setting) consiste na análise do grau de ênfase colocado em alguns dos assuntos e atributos reportados, o que contribui para salientar esses assuntos e influenciar a prioridade atribuída a eles pelo público ${ }^{35}$. Por extensão dessa teoria, a construção de agenda examina o interjogo entre as fontes e seus efeitos potenciais na promoção das ênfases ${ }^{36}$ para vislumbrar a maneira como os consumidores de notícia valorizam, em diferentes graus e modos, os assuntos elencados pela imprensa, como já propunham Maxwell Mc Coombs e Donald Shaw na década de 1970.

Portanto, quanto maior seja a proeminência da cobertura nos meios de um determinado assunto, maior será a importância que o público há de avaliar que o assunto tem. A teoria também estabelece que a mídia impacta em quais assuntos serão considerados 'importantes' pelo público, mas não necessariamente na forma como o público avalia tais assuntos ${ }^{37}$.

A configuração de agenda assume a existência de uma relação recíproca ou ciclo interativo e de reforço mútuo entre agentes da elite (p. ex.: científica e política), a mídia e o público ${ }^{18,38}$. Argumenta-se que a abordagem sugere que o conteúdo das notícias não é moldado, em sentido estrito, na sala de notícias, mas nas fontes que entregam informação aos jornalistas. 
Ainda que a contribuição do jornalismo para a construção de narrativas na imprensa intente refletir a complexidade de diferentes contextos da sociedade, nenhuma das duas abordagens discutidas é imune a problemas analíticos e empíricos. Por um lado, o próprio Entman ${ }^{32}$, por exemplo, indica que os estudos iniciais de enquadramento se dedicaram a descrever a especificidade do contexto analisado em detrimento de uma operacionalização que pudesse ser aplicada de forma geral e padronizada. No caso dos estudos de configuração de agenda, poucas vezes considera-se sua não linearidade, ou seja, as interações multifacéticas das agendas com diferentes instituições e as realimentações mútuas. Estudam-se, por exemplo, diferentes níveis nessa construção interconectada e cada vez mais complexa: "second-level" ou "third-level agenda-setting" 35 (p. 65). Por outro lado, nenhum desses instrumentos teórico-empíricos reflete totalmente os impactos da construção cultural da ciência pela mídia, ou seja, as formas de criação de sentido (sensemaking) - os significados, emoções e experiências transmitidas pela mídia - como conseguem outras abordagens de base culturalista e construtivista dedicadas ao estudo das narrativas na mídia por meio da análise de discurso ${ }^{39}$.

\section{MÉTODOS}

Neste trabalho de análise de conteúdo, a unidade da análise utilizada é cada matéria individual em MR na imprensa brasileira em um determinado período de tempo. Primeiro, foram identificados os títulos das matérias e o parágrafo inicial para constatar a sua relação com os relatos.

Segundo, os textos foram lidos e classificados, de forma manual e com checagem por um segundo pesquisador da equipe de pesquisa, entre os de caráter nacional e internacional, para determinar qualitativamente se os textos nacionais traziam influências internacionais ressignificadas localmente. Quando a informação é internacional, existe um processo de reacomodação que se reflete em um processo de adaptação à ideologia dos jornalistas e na redefinição da informação no espaço jornalístico ${ }^{40}$.

Terceiro, se estabeleceu uma primeira grande classificação entre os enquadramentos de caráter científico-técnico e médico e aqueles de cunho social. Dentro da categoria social, existem quatro dimensões mais específicas, segundo uma reformulação da tipologia desenvolvida por Nisbet; Brossard; Kroepsch ${ }^{23}$. Os códigos finais utilizados se basearam nos seguintes enquadramentos: a) avanços científico-técnicos e médicos: relatos que reportam conferências ou pesquisas com descobertas ou novidades; b) ética: matérias com foco na religião ou em valores morais; c) regulatória e de política pública: textos sobre leis, regulação e políticas públicas; d) assuntos econômicos ou financeiros: matérias sobre direitos de propriedade intelectual, custos, preços, competição e; e) perspectiva humanista, que foca na narrativa de indivíduos ou grupos que se beneficiariam da PCT. As quatro últimas categorias fazem parte do enquadramento social.

Quarto, as valências ou tons das reportagens foram definidas por meio de uma versão modificada de Yoon $^{41}$ sobre a cobertura das notícias em PCT. Cada relato foi classificado como otimista, pessimista ou neutro/descritivo, e se investigou as origens ou fontes dessas predições onde existiam. Um artigo era codificado como otimista se a maioria da informação reportasse contribuições da MR ou de debates a favor, seguindo palavras-chave como: sucesso, confiança, ajuda e benefício. $\mathrm{O}$ termo pessimista se referia à desaprovação da MR na maioria do relato ou à reportagem de aspectos do debate que colocam obstáculos à pesquisa ou à aprovação e comercialização da TC, eram procuradas palavras-chave como: medo, crítica, preocupação, dúvida, risco/perigo e revés. Quando a maioria dos parágrafos não era nem otimista nem pessimista, ou quando havia um balanço entre os atributos otimistas e pessimistas, se considerava o artigo como neutro ou descritivo.

Quinto, as fontes dominantes citadas das informações em cada matéria foram classificadas como de elite e não elite, segundo uma modificação da categorização de Fahmy, Kelly e Wanta ${ }^{18}$, para introduzir aspectos culturais relevantes. As quatro categorias resultantes no primeiro grupo, de elite (de maior poder), são: cientistas e médicos do setor público/privado; agentes de políticas públicas; representantes da indústria; 
fontes internacionais - incluindo gerentes e cientistas/médicos estrangeiros; as três do segundo grupo, de não elite, incluem: representantes de organizações não governamentais (ONGs) e grupos de advocacia, cidadãos e fontes anônimas.

Sexto, se estabeleceu um paralelo entre as fontes e as instituições citadas nos relatos. As fontes se classificaram como: públicas, privadas ou mistas (ex.: parcerias público/privadas - PPP), e também se exploraram, de modo qualitativo, o tipo de instituições envolvidas.

\section{O ESTUDO DE CASO}

\section{Descrição da amostra}

Entre janeiro de 2012 e maio do 2019, foram coletadas 39 matérias em MR nos jornais nacionais: Folha de S.Paulo e O Globo, sendo descartados três relatos por serem irrelevantes. A busca nos sítios dos jornais se realizou utilizando duas palavras-chave: 'terapia celular' e 'terapia com células-tronco', e por meio dos links <https://www.folha.uol.com.br/> e <https://oglobo.globo.com/>.

A seleção dos jornais obedece ao critério de maior circulação, um impacto importante no Brasil em nível nacional e a presença de seções específicas para a publicação de matérias científicas e médicas. Os jornais de elite contribuem para estabelecer uma agenda para os não de elite e usam um maior número de recursos e fontes. O período da amostra selecionada reflete o tempo em que, havendo-se desenvolvido em anos anteriores resultados de pesquisa básica e pré-clínica, o campo volta-se, em grande medida, ao estudo da fase clínica em TC, o estágio principal da MR em nível global.

\section{Características gerais}

A análise da imprensa corresponde a um total de 36 matérias, das quais 29 são da Folha de S.Paulo e 7 do Globo, ou seja, a Folha publicou quatro vezes mais relatos da MR do que o Globo. A distribuição por título da matéria, tipo de gênero jornalístico e data da publicação em cada jornal é apresentada nos Quadros 1 e 2, a seguir:

\section{Quadro 1 - Notícias no jornal Folha de S.Paulo sobre terapia celular*}

\begin{tabular}{|l|l|l|l|}
\hline \multicolumn{2}{|c|}{ Manchete } & \multicolumn{1}{c|}{ Formato } & \multicolumn{1}{c|}{ Data } \\
\hline 1 & $\begin{array}{l}\text { Clínicas vendem protocolo 'Kardashian' de transfusão que rejuvenesce sem } \\
\text { eficácia }\end{array}$ & Reportagem & $29 / 03$ \\
\hline 2 & Governo de SP estuda parceria entre Butantan, USP e farmacêutica Novartis & Notícia & $23 / 01$ \\
\hline 3 & Como se prevenir das doenças infecciosas para as quais não há vacina & Reportagem & $05 / 01$ \\
\hline 4 & Farmacêutica Novartis investirá R\$ 1 bilhão nos próximos cinco anos & Notícia & $11 / 09$ \\
\hline 5 & Cientistas de SP testam células-tronco para tratar incontinência urinária & Reportagem & $26 / 09$ \\
\hline 6 & Novas técnicas criam ossos e cartilagens à la carte & Notícia & $06 / 04$ \\
\hline 7 & Células-tronco são testadas como terapia contra impotência & Reportagem & $27 / 03$ \\
\hline 8 & Cientistas de SP testam células-tronco para tratar incontinência urinária & Reportagem & $26 / 09$ \\
\hline 9 & Edição de DNA em embriões humanos feita nos EUA é confirmada por revista & Reportagem & $02 / 08$ \\
\hline 10 & Edição de DNA é usada em embriões humanos pela 1a vez nos EUA & Notícia & $27 / 07$ \\
\hline
\end{tabular}




\begin{tabular}{|l|l|l|l|}
\hline \multicolumn{2}{|c|}{ Manchete } & \multicolumn{1}{|c|}{ Formato } & \multicolumn{1}{c|}{ Data } \\
\hline 11 & Entidade de vereador é paga para levar doentes para a Tailândia & Reportagem & $20 / 03$ \\
\hline 12 & Cientistas criam técnica que controla diabetes em camundongos sem injeção & Notícia & $10 / 12$ \\
\hline 13 & Conexão cérebro-máquina faz paraplégico mexer perna, diz estudo & Reportagem & $11 / 08$ \\
\hline 14 & Cães da USP 'escapam' de distrofia muscular e podem ser chave para a doença & Reportagem & $13 / 11$ \\
\hline 15 & Hospital Albert Einstein recebe certificação internacional & Notícia & $29 / 10$ \\
\hline 16 & Terapia gênica renova esperanças para enfrentar a Aids e o câncer & Reportagem & $23 / 08$ \\
\hline 17 & Apenas 0,01\% dos cordões umbilicais de bancos privados tiveram uso & Reportagem & $31 / 01$ \\
\hline 18 & $\begin{array}{l}\text { Geneticista da USP defende venda de substâncias geradas a partir de células- } \\
\text { tronco }\end{array}$ & Reportagem & $27 / 12$ \\
\hline 19 & Brasil tem 10 caso de sucesso em terapia celular contra doença de Crohn & Reportagem & $15 / 05$ \\
\hline 20 & Pesquisas buscam maior qualidade de vida para paraplégicos e tetraplégicos & Reportagem & $12 / 05$ \\
\hline 21 & É inútil guardar célula-tronco em bancos privados de cordão & Reportagem & $14 / 01$ \\
\hline 22 & Butantan testa uso de células-tronco para implantes dentários & Notícia & $27 / 07$ \\
\hline 23 & Restrição para doar medula divide médicos e pacientes & Reportagem & $01 / 07$ \\
\hline 24 & Anvisa lança guia sobre armazenamento de sangue de cordão umbilical & Notícia & $24 / 05$ \\
\hline 25 & Armazenamento de cordão umbilical se populariza no Brasil & Reportagem & $10 / 03$ \\
\hline 26 & Injeção de célula-tronco humana devolve audição a roedor surdo & Notícia & $13 / 09$ \\
\hline 27 & $\begin{array}{l}\text { Uso de técnicas "cérebro-máquina" em oposição à terapia celular para } \\
\text { tratamento de pessoas com paralisia }\end{array}$ & Reportagem & $17 / 12$ \\
\hline 28 & Terapia com células-tronco recupera ereção em camundongos & Notícia & $27 / 01$ \\
\hline 29 & $\begin{array}{l}\text { Júlio César Voltarelli, da USP, foi um dos primeiros a realizar o procedimento no } \\
\text { Brasil }\end{array}$ & Notícia & $22 / 03$ \\
\hline
\end{tabular}

Fonte: A autora (2019).

*Nota: Notícia: conteúdos factuais de caráter informativo; a notícia tem um prazo curto de validade no qual, as informações devem ser consumidas de imediato; reportagem: gênero textual no qual, além do caráter informativo, é incluído o estudo de causa ou efeito de algum assunto que já foi uma notícia e muitas vezes, inclui entrevistas.

\section{Quadro 2 - Notícias no jornal O Globo sobre terapia celular*}

\begin{tabular}{|l|l|l|l|}
\hline \multicolumn{2}{|c|}{ Manchete } & Formato & Data \\
\hline 1. & $\begin{array}{l}\text { Terapia genética, imunoterapia e nanotecnologia são novos instrumentos no } \\
\text { combate ao câncer }\end{array}$ & Reportagem & $04 / 02$ \\
\hline 2. & Tratamento experimental freia esclerose múltipla & Notícia & $31 / 03$ \\
\hline 3. & INC faz palestra sobre terapia celular para o coração & Notícia & $3 / 03$ \\
\hline 4. & INTO faz pesquisa para desvendar a artrose & Notícia & $07 / 11$ \\
\hline 5. & Centro de Tratamento de Terapia Celular & Notícia & $25 / 02$ \\
\hline 6. & Santa Casa e universidade canadense vão estudar vacina contra câncer & Notícia & $11 / 11$ \\
\hline 7. & Pesquisas com células-tronco entre a ousadia e a cautela & Reportagem & $04 / 10$ \\
\hline
\end{tabular}

Fonte: A autora (2019).

* Nota: Notícia: conteúdos factuais de caráter informativo; a notícia tem um prazo curto de validade, no qual as informações devem ser consumidas de imediato; reportagem: gênero textual no qual, além do caráter informativo, é incluído o estudo de causa ou efeito de algum assunto que já foi uma notícia e muitas vezes, inclui entrevistas. 
Na Folha de S.Paulo, 58\% das matérias correspondem a reportagens, e as restantes são notícias (Quadro 1). No caso do jornal O Globo, a maioria das matérias é apenas notícia e, em geral, mais breves do que na Folha (Quadro 2). É interessante observar que não existem entre essas matérias nenhuma que possa ser classificada no gênero jornalístico de 'artigo', ou seja, que consista em um material jornalístico contendo a opinião pessoal, avaliativa e crítica do jornalista e que constitua um produto mais extenso. A exclusividade desses dois gêneros jornalísticos - reportagens e notícias - revelam a influência de conceitos editoriais dos jornais e/ou dos treinamentos/práticas habituais dos jornalistas, também incentivadas no seu entorno ou meio. Além disso, os gêneros limitam a apresentação detalhada do material informativo em MR e o tornam mais breve no caso das notícias, e menos completo e crítico no caso das reportagens. Os relatos curtos, de entre 1.000 e 1.500 palavras, são acompanhados frequentemente de algum material gráfico ou visual: a descrição de uma técnica, tratamento ou descoberta científica ou, ainda, de alguma foto de um indivíduo com uma doença tratável pela MR e/ou beneficiado pela sua aplicação. Contudo, Mas uma análise qualitativa das imagens utilizadas supera o escopo deste artigo e nossas habilidades profissionais, ainda assim, alguns deles serão comentados de forma breve quando formem parte essencial do argumento apresentado pelas matérias.

A maior percentagem dos textos corresponde ao ano de 2013 (Tabela 2). Observa-se um declínio considerável nas matérias a partir do ano de 2016. Essa situação corresponde à transformação das prioridades nacionais de acordo com as mudanças políticas decorrentes daquele momento (ex. impeachment da Presidenta Dilma Rousseff e mandato do Vice-presidente Michel Temer), como também, a mudança na condução do organismo financiador principal das pesquisas: o Departamento de Ciência e Tecnologia (DECIT) da Secretaria de Ciência, Tecnologia e Insumos Estratégicos (SCTIE) do Ministério da Saúde.

Tabela 2 - Evolução das matérias publicadas, anos 2012-2019 (em números)

\begin{tabular}{lccccccccc}
\hline Ano/mídia & 2012 & 2013 & 2014 & 2015 & 2016 & 2017 & 2018 & 2019 & Total \\
\hline O Globo & 1 & 1 & - & 3 & - & - & 1 & 1 & 7 \\
$\begin{array}{l}\text { Folha de } \\
\text { S.Paulo }\end{array}$ & 4 & 5 & 4 & 5 & 3 & 3 & 3 & 2 & 29 \\
Total & $\mathbf{6}$ & $\mathbf{1 2}$ & $\mathbf{6}$ & $\mathbf{1 0}$ & $\mathbf{3}$ & $\mathbf{5}$ & $\mathbf{4}$ & $\mathbf{5}$ & $\mathbf{3 6}$ \\
\hline
\end{tabular}

Fonte: Dados de pesquisa, janeiro de 2012 e maio do 2019 (2020)

Chama a atenção a grande variedade de assuntos da cobertura midiática sobre descobertas científicas e médicas, assim como, que os relatos se concentram em relativamente poucas doenças e menos proeminentes em nível internacional. As doenças mais frequentemente estudadas na atualidade em nível global são: diferentes tipos de câncer, doenças neuronais ou neurodegenerativas, cardíacas, oculares (da retina e da mácula) e doenças $\operatorname{raras}^{27}$.

Há, nas matérias analisadas nos dois jornais, um predomínio de relatos sobre o sangue do cordão umbilical (4) e, em segundo lugar, de lesões medulares (3); alguns dos transplantes de medula óssea (2), da edição de genes (2) e da disfunção erétil (2). Após isto, relata-se uma grande variedade de assuntos, como: os tratamentos ósseo-musculares, de cartilagem e dentais, problemas estéticos, a doença de Crohn, a diabetes, as vacinas e a incontinência urinária e eréctil.

Se misturam nos relatos, com frequência e pouca precisão, duas dimensões da MR: as aplicações em células-tronco, em sentido estrito, e as terapias gênicas. Isto pode refletir alguma negligência dos jornalistas na interpretação e validação da informação. Mas também se deve a que, às vezes, os dois tipos de terapias praticam-se em conjunto. 
Quanto à qualidade dos relatos, ela foi avaliada apenas de forma qualitativa através de uma leitura sistemática. Observa-se que os jornalistas tendem a não fundamentar as matérias com estatísticas ou metodologias substantivas, em consonância com achados de outros estudiosos da imprensa brasileira em ciência e saúde e da América Latina ${ }^{42-44}$. O caráter das matérias costuma ser descritivo; não mais de um terço de relatos apresentam quadros ou gráficos explicativos e, sem excessivo jargão, o que os tornaria de difícil compreensão pública. No caso das matérias sociais, poucas vezes as fontes de informação se contrastam de modo sistemático, inclusive quando existe alguma controvérsia importante. Reportam-se debates em um total de 10 matérias, ou seja, em apenas $27,7 \%$ do total das matérias na imprensa analisada. Isto corresponde, sem dúvidas ao escasso preparo da maioria dos jornalistas científicos que carecem de formação específica em ciência e/ou em MR ${ }^{44}$.

\section{Análise de conteúdo das matérias}

Existe uma tendência diferencial significativa entre a origem do conteúdo das matérias dos dois jornais analisados. Enquanto na Folha de S.Paulo predominam os relatos de cunho internacional, O Globo reporta sucessos ou eventos nacionais. Nele, encontra-se apenas um artigo internacional versus 16 na Folha de S.Paulo.

Esta constitui uma tendência bastante oposta aos resultados de análise em contextos europeus, onde a imprensa faz prevalecer matérias sobre a pesquisa e a terapia local ${ }^{4}$. Ainda assim, ela se corresponde com conclusões de outros trabalhos acadêmicos associados da América Latina e de outras regiões ${ }^{40,45}$. A qualidade 'periférica' ou subordinada' na divisão internacional do trabalho em ciência nos países emergentes, acarreta um orçamento limitado para essas atividades, uma dissociação considerável entre os interesses em saúde locais e os assuntos pesquisados, assim como, um menor reconhecimento global das capacidades dos cientistas locais. Estabelece-se assim, uma dependência excessiva das fontes internacionais em detrimento da informação ligada novidades locais, que no caso brasileiro, são substantivas em MR (consultar, por exemplo $\left.{ }^{15}\right)$.

Também observou- se, em nível qualitativo, que as fontes originais de alguns dos textos são revistas de prestígio internacional, como Nature, Science, New England Journal of Medicine e MIT Technology Review, que costumam enviar comunicados de imprensa aos jornais. Nesses casos, ainda que os assuntos reportados tendam a ser homogêneos, reacomoda-se o sentido da informação por meio de referências ou analogias com a realidade local; resultado semelhante ao encontrado em outros estudos da imprensa brasileira $^{40}$.

Nos enquadramentos predomina o de caráter científico-técnico e médico $(61 \%, 22$ matérias) e o de cunho social, representando mais de um terço do total de artigos (14 matérias). Na diferenciação entre as diversas categorias secundárias de enquadramentos sociais, um pouco menos da metade corresponde ao caráter regulatório ou de política pública - e devido em parte à falta de transparência sobre as iniciativas e debates contemporâneos em MR em nível local. A seguir, será especificada a análise das matérias segundo cada categoria em cada jornal.

A Folha de S.Paulo foca na descrição dos 'avanços científico-técnicos e médicos', das novidades ou descobertas em $62 \%$ das matérias (18 relatos no total), ainda que com diferentes graus de profundidade e validação do reportado. Na distribuição do conteúdo dos temas dos 'artigos sociais' na Folha, em 37,9\% (11 no total), predominam os relatos sobre 'política pública em nível de regulamentação' (7 textos). Três desses textos sociais classificam-se no 'enquadramento de natureza econômico/financeira', já que se centram nos custos reais ou potenciais das TC e/ou problemas na sua comercialização futura. Apenas uma matéria refere-se a 'assuntos da bioética' e responde ao caso da denúncia de um vereador envolvido de modo econômico fraudulento como intermediário no turismo médico à Tailândia. Destaca-se que, nesta 
mídia, se carece de artigos desenvolvidos a partir de 'uma perspectiva humanista/humanitária', baseados na narrativa de indivíduos ou grupos que possam vir a se beneficiar das TC. Apenas um texto social faz referência a uma controvérsia regulatória nacional e com ampla divulgação: a fixação governamental de quotas para a doação de sangue da medula óssea para transplantes, devido a limitações burocráticas e infraestruturais para seu armazenamento.

A reiteração dos relatos que se referem à coleta e uso do sangue do cordão umbilical e da placenta reflete um alto interesse público e uma preocupação governamental com o controle regulatório. A expansão, na última década, no número e nas atividades dos bancos privados no território nacional e seu marketing à população de forma insistente e pouco fidedigna sobre os benefícios desse sangue, junto aos altos custos dessa forma de armazenagem, têm levado a Agência Nacional de Vigilância Sanitária (Anvisa) a desenvolver ações concretas - campanhas publicitárias e cartilhas informativas - de divulgação à população, apresentando estatísticas fidedignas.

Resulta também relevante que, no total dos textos publicados na Folha de S.Paulo, apenas em um terço das matérias ( 9 casos) se menciona o custo real ou potencial das aplicações terapêuticas da MR, apresentando-se, desse modo, um panorama pouco pragmático e realista aos leitores - tendência também observada por outros acadêmicos em nível global ${ }^{25-26}$. Ainda assim, os custos que se informam nas matérias analisadas costumam ser, pelo menos, a metade dos existentes no mercado global para TC semelhantes ou dos estimados no futuro. Uma causa disso é que as estimativas das matérias se baseiam muitas vezes em cálculos de apenas uma injeção de TC, quando um tratamento requer frequentemente entre 6 e 14 ciclos - o qual não se específica com claridade nas matérias.

No Globo, a tendência descrita se mantém no predomínio de 'artigos científico-técnicos e médicos' (57\%, 4 casos), apesar do escasso número de relatos. Entre as três matérias publicadas de 'tipo social', duas referem-se à 'política pública', e outra é com 'perspectiva humanista/humanitária', a única deste gênero na imprensa analisada. Esta relata o doloroso percurso de um paciente até conseguir um medicamento eficaz de base celular para o câncer, fora do Brasil. Nesse sentido, alude-se a uma crítica relativa à política pública local na MR. Nela, se incentiva até certo ponto o desenvolvimento da TC, mas colocam-se vastos impedimentos para a sua aprovação.

Nos dois jornais, observa-se a escassez de visão humanista nas matérias, em contraste com tendências comprovadas em outros contextos da $\mathrm{MR}^{46}$. Os jornais de elite tendem a priorizar as informações 'duras' versus as 'brandas'. As dificuldades enfrentadas pelos doentes são deixadas para ser reportadas pela imprensa popular ${ }^{22}$, os sítios $w e b$ das associações de pacientes e de beneficência ${ }^{15}$, ou os vídeos do YouTube ${ }^{47}$. Esse tipo de narrativa é mais frequente em veículos midiáticos que entrevistam pacientes e familiares como testemunhas, por exemplo, na televisão, em que se enfatizam os resultados positivos de seus processos de cura mediante a utilização de imagens visuais de alto impacto ${ }^{6}$. A ausência de fontes ou menção às organizações civis envolvidas na MR nas matérias - e de grande atividade e relativa importância nacional - também contribui para a escassez desse tipo de narrativa humanista.

É significativa a falta de textos baseados em avaliações morais e bioéticas, ainda que também se encontrem em diminuição em nível global, uma vez superadas em muitos países as controvérsias regulatórias em relação ao status do embrião ${ }^{48,24}$. A desinformação sobre assuntos bioéticos pode vir a resultar em um grande inconveniente para a população interessada e restringir o controle cidadão adequado do desenvolvimento das pesquisas e do seguimento de seus resultados.

Na Folha de S.Paulo, mais da metade dos artigos é otimista em relação aos benefícios da MR (16 casos), com 8 pessimistas e apenas 5 neutros; uma tendência frequente na literatura associada e que enfatiza de modo dominante o progresso científico e médico ${ }^{24,27}$. No caso do Brasil, reforça-se assim a identidade científica nacional, quiçá em parte como reação defensiva e de oposição social à desvalorização e às muitas 
desvantagens que acompanham o papel 'subordinado' atribuído à ciência local em nível global, e suas implicações negativas sobre a construção da identidade profissional.

Influi na quantificação dos textos como pessimistas a fixação governamental de restrições para as doações de sangue da medula óssea para transplantes e a notícia do vereador com participação econômica fraudulenta no turismo médico, casos já mencionados; relatos negativos da Anvisa e do Conselho Federal de Medicina (CFM) sobre algumas aplicações estéticas da TC, e as matérias alertando a população sobre o marketing inadequado no armazenamento do sangue do cordão umbilical em bancos privados. Em contraste, no Globo, os artigos se distribuem entre quatro de carácter neutro e três otimistas e, possivelmente, devido à escassez de textos, se detectou apenas um padrão associativo aleatório entre as valências dos textos e os dois tipos principais de enquadramentos.

Para a análise das fontes das notícias, estabeleceu-se um paralelo entre os informantes e as instituições citadas nos artigos. Há de se notar a alta proporção de matérias que se referem a parcerias público-privadas (PPP): 52\% - de um total de 19 artigos nos dois jornais. Isso pode vir a refletir a influência da promoção estatal nessa direção na área da saúde na última década ${ }^{49}$. Essa situação revela também a maior dependência do setor do financiamento privado na fase de altos custos dos ensaios clínicos em TC ${ }^{15}$. O Estado intenta promover a inclusão do financiamento privado na MR devido à necessidade de alto investimento para a realização de ensaios clínicos, fase 3, mas esse processo ainda têm resultados relativos. Em segundo lugar, figuram aquelas matérias baseadas em atividades científico-médicas públicas (8), que reportam avanços nas pesquisas pré-clínicas, em contraste com as atividades privadas de empresas e hospitais renomados (9).

De forma quase excludente, são as instituições de elite as que informam as matérias nos dois jornais. Por um lado, parece que os jornalistas utilizam apenas fontes altamente 'confiáveis' ou das instituições de notoriedade social. Por outro lado, a exclusão de representantes das organizações civis locais e internacionais relevantes como fontes primárias tem sido muito frequente em todas as atividades da área - com exceção do debate nacional em relação à aprovação da regulamentação das pesquisas com células tronco embrionárias, que se estendeu por vários anos em meados da primeira década dos anos 2000.

Quase não existem nos textos dados baseados exclusivamente nas fontes classificadas como não de elite, com isenção de três casos de matérias com fontes anônimas publicadas na Folha. Em um terço das matérias nos dois jornais (11 casos), mencionam-se como relevantes - mas não como fontes - organizações da sociedade civil, principalmente associações profissionais médicas. Mas sempre as referências aparecem em conjunto com outras instituições de elite.

Ainda assim, as instituições de elite mais mencionadas nos artigos nem sempre correspondem às mais ativas na MR local ${ }^{15}$, o que se deve também ao nível diferencial de utilização de centros/profissionais de relações públicas pelas universidades públicas para a divulgação dos resultados científicos. É citada - em menor proporção - a participação de universidades estrangeiras escolhidas como parceiras em algumas iniciativas locais, p. ex.: a Universidade de Laval, no Canadá, algumas americanas: a Universidade de Saúde e Ciência de Oregon, de Duke, Califórnia, de Harvard e Brown, além das europeias, como Sheffield e Tulane. Ainda assim, a importante função desempenhada pelos programas de cooperação internacional da Fapesp nesta área é obscurecida nas matérias analisadas, ainda que seja relevante na divulgação digital - o recurso midiático preferido atualmente por muitas instituições associadas à MR.

Mencionam-se também os principais hospitais públicos, o Inca e o Incor e privados - o Hospital Albert Einstein e o Instituto Butantan - que são centros de excelência global em MR, em especial, em ensaios clínicos. Entre as empresas privadas citadas, merece destaque a Novartis pelo grande investimento recente na MR brasileira. Ainda assim, aparecem em menor medida os bancos privados de sangue de cordão umbilical: Cryopraxis e Cordvida. É interessante salientar a menção à recente entrada no campo da MR, atuando em parceria, de outras empresas farmacêuticas transnacionais, como: Interfarma, Sidesfarma, LabStemcorp e o Bonus Biogroup - inclusão que é fomentada atualmente de maneira ampla pelo Estado. 
A referência às empresas transnacionais corresponde a mais da metade dos artigos focados na TC, em um momento em que se pretende acelerar sua inclusão na MR para assegurar um investimento mais significativo no setor.

Pode-se encontrar também um número significativo de matérias apenas sobre PCT e, em uma proporção bem menor, aqueles que são tão genéricos que não especificam, de forma fidedigna, o estágio da descoberta científica relatada.

As fontes não de elite, em sentido estrito - sete casos do total, incluindo as fontes anônimas correspondem a representantes de sociedades de pacientes e seus familiares: a Associação Brasileira de Linfoma e Leucemia e a Sociedade Nacional de Esclerose Múltipla, assim como, duas sociedades de beneficência (ONGs). Por outro lado, os cidadãos, em geral pacientes, são citados/entrevistados como exemplo dos sucessos das terapias, na procura delas, ou como participantes em ensaios clínicos, em apenas mais de um terço do total dos textos (13 casos). Essas duas questões mostram uma tendência à escassa inclusão dos grupos não privilegiados como informantes na área - em parte, reflexo do papel das iniquidades estruturais socioeconômicas e em ciência - como assinalam outros acadêmicos interessados na comunicação pública da MR ou da ciência e a medicina em geral ${ }^{25}$, e também, ressalta a forma prioritária de promoção do entendimento público da ciência desde um modelo do 'déficit' - atribuído aos conhecimentos dos leigos versus os especializados - e uma direcionalidade na estratégia de comunicação em ciência de estilo vertical.

\section{CONSIDERAÇÕES FINAIS}

A análise mostrou as limitações nas informações sobre MR que aparecem na imprensa brasileira de elite: um número bastante escasso de artigos, de tons às vezes otimistas demais, enfatizando principalmente os benefícios das pesquisas e TC; com tendência a omissões do debate global sobre os riscos e incertezas desse campo. Os imaginários sociais e os investimentos reais destinados à ciência/medicina nos contextos estaduais influem no número de matérias publicadas em cada jornal. A qualidade dos relatos, ainda que aceitável, aparece como mais descritiva do que crítica.

Nas matérias, intenta-se algum reajuste das informações internacionais à realidade local, apesar da alta dependência daquelas fontes. A qualidade dos conteúdos constata-se como bastante desatualizada e de curta preparação em referência aos avanços locais em MR, ainda que se utilizem como fontes ou referências as instituições públicas mais prestigiosas em nível nacional. Há uma escassa aplicação de instrumentos do jornalismo investigativo - o relevo de informação ampla junto a diversos grupos de interesse. Faltaria uma contribuição mais sistemática da imprensa à legitimação social e institucional desta área de ponta no país, que se desenvolveu durante décadas com recursos públicos e grande dedicação profissional, oferecendo uma oportunidade imperdível para a inclusão competitiva do Brasil no cenário global ${ }^{15}$.

Outros três aspectos impactam nos resultados obtidos: a) a relevância média das matérias sobre políticas públicas e que desinformam sobre mudanças regulatórias recentes na MR global e local50; b) a escassez de conteúdos voltados a assuntos éticos, específicos desta nova fase da TC; c) a ausência de textos com uma visão humanista - resultados que se alinham com outros no estudo da imprensa científica na América Latina $^{42,40}$ e da MR em outras regiões ${ }^{48,25}$.

O debate ético e regulatório constitui-se como central na fase atual de desenvolvimento das TC e da sua entrada no sistema público de saúde e no mercado, no curto e médio prazo. Se a mídia local não contribui nessa direção, os setores sociais que se informam sobre ciência pelos jornais impressos de elite vão carecer de evidências suficientes para uma tomada de decisões informada em saúde e para uma participação pública ativa na formulação, implementação e seguimento das políticas públicas. Essa situação é preocupante para a saúde coletiva, a democratização da ciência e o fortalecimento dos direitos cidadãos. 
A informação que a imprensa de elite oferece costuma ser uma das fontes principais de outras mídias da internet e da televisão - mais amplamente consultadas, assim como serve como insumo para matérias publicadas na imprensa popular. Ou seja, seus conteúdos podem vir a afetar o entendimento/engajamento público em MR de setores mais amplos da população local, em especial, em áreas inovadoras. Porém, a comprovação estrita desses aspectos merece um aprofundamento mediante nova pesquisa.

\section{REFERÊNCIAS}

1. Schäfer MS. Taking stock: A meta-analysis of studies on the media's coverage of science. Public Underst Sci. 2012;21(6):650-63.

2. Bastos MT. Medium, media, mediação e midiatização: a perspectiva germânica In: Mattos MA, Janotti Junior J, Jacks N, organizadores. Mediação \& Midiatização. Salvador: EDUFBA; 2012, p. 59-68.

3. Martín-Barbero J. Dos meios às mediações: comunicação, cultura e hegemonia. Rio de Janeiro: UFRJ; 1997.

4. Dumas-Mallet E. Do newspapers preferentially cover biomedical studies involving national scientists? Public Underst Sci. 2019;28(2):191-200.

5. Percepção pública da C\&T no Brasil: 2019: resumo executivo [Internet]. Brasília, DF: Centro de Gestão e Estudos Estratégicos; 2019 [citado em 2020 out. 15]. Disponível em: https://www.cgee.org.br/ documents/10195/734063/CGEE resumoexecutivo Percepcao pub CT.pdf.

6. Acero L. Uma análise de matérias televisivas em ciência: o caso da medicina regenerativa no Brasil. Rev Tec Soc. 2020;16(45):76-91.

7. Acero L. News on regenerative medicine in Brazil: the quality of press reports. J Genet Cell Biol. 2020;3(2):162-8.

8. Barba MLP, González JP, Massarani L. Diagnóstico de la divulgación de la ciencia en América Latina: Uma mirada a la práctica en el campo. Leon: Fibonacci Innovación y Cultura Científica; RedPOP; 2017.

9. Guenther L, Joubert M. Science communication as a field of research: identifying trends, challenges and gaps by analyzing research papers. J Sci Commun. 2017;16(02):A02.

10. Massarani L, Buys B. Science in the press in nine Latin American Countries. Braz Journalism Res. 2007;3(2):77-96.

11. Elmer $\mathrm{C}$, Badenschier $\mathrm{F}$, Wormer $\mathrm{H}$. Science for everybody? How the coverage of research issues in German newspapers has increased dramatically. Journalism Mass Commun Q. 2008; 85(4):878-93.

12. Haran J, Kitzinger J, McNeil M, et al. Human cloning in the media: from science fiction to science practice. London: Routledge; 2007.

13. Haran J, Kitzinger J. Modest witnessing and managing the boundaries between science and the media: A case study of breakthrough and scandal. Public Underst Sci. 2009;18(6):634-52.

14. Acero L. Science, public policy and engagement: debates on stem cell research in Brazil. Genom Soc Policy. 2010;6(3):1-17.

15. Acero L. Pesquisas e terapias com células-tronco: visões sociais e o debate no brasil. Rio de janeiro: e-papers; 2011.

16. Jurberg C, Verjovsky M, Machado GOC, et al. Embryonic stem cell: A climax in the reign of the brazilian media. Public Underst Sci. 2009;18(6):719-29.

17. Reis R. How Brazilian and North American Newspapers Frame the Stem Cell Research Debate. Sci Communic. 2008;29(3):316-34.

18. Fahmy S, Kelly JE, Wanta W. President power to frame stem cell views limited. Newspaper Res J. 2010;31(3):62-74.

19. Santiago RL. Lei, mídia e meio ambiente: um estudo a partir das pesquisas envolvendo célulastronco embrionárias e a influência dos meios de comunicação na aprovação da Lei n 11.105/2005 [dissertação]. Curitiba: Pontifícia Universidade Católica do Paraná; 2007. 
20. Leydesdorff $\mathrm{L}$, Hellsten L. Metaphors and diaphors in science communication: mapping the case of stemcell research. Sci Commun. 2005;27(1):64-99.

21. Marks L, Kalaitzandonakes N, Wilkins L, et al. Mass media framing of biotechnology news. Public Underst Sci. 2007;16:183-203.

22. Caulfield T. Biotechnology and the popular press: hype and the selling of science. Trends in Biotechnol. 2004;22:337-9.

23. Nisbet $M$, Brossard D, Kroepsch. Framing science: the stem cell controversy in an age of press/politics. Inter J Press Polit. 2003;8:36-70.

24. Kamenova K, Caulfield T. Stem cell hype: media portrayal of therapy translation. Sci Transl Med. $2015 ; 7(278): 278-82$

25. Kamenova K. Media portrayal of stem cell research: towards a normative model for science communication. Asian Bioethics Rev. 2017;9(3):199-209.

26. Lynch J. Bridging science and journalism: identifying the role of public relations in the construction and circulation of stem cell research among laypeople. Sci Commun. 2014;36(4):479-501.

27. Bubela T, Li MD, Hafez M, et al. Is belief larger than fact: Expectations, optimism and reality for translational stem cell research. BMC Med. 2012 Nov 6;10:133-43.

28. D'Angelo P. News framing as a multi-paradigmatic research program: a response to entman. J Commun. 2002;52(4):870-88.

29. Gofman E. Framing analysis: an essay on the organization of experience. Boston: Northeastern University Press; 1974.

30. Gome M. O conceito de enquadramento noticioso nos estudos publicados em periódicos científicos (2013-2016) [Internet]. In: Anais do $40^{\circ}$ Congresso Brasileiro de Ciências da Comunicação; $40^{\circ}$ Intercom: Sociedade Brasileira de Estudos Interdisciplinares da Comunicação; 2017 set. 04-09; Brasil, Paraná. Curitiba: Universidade Positivo; 2017 [citado em 2020 out. 15]. Disponível em: https:// portalintercom.org.br/anais/nacional2017/resumos/R12-2928-1.pdf.

31. Baresch B, Hsu SH, Reese S. The power of framing: new challenges for researching the structure of meaning in news. In: Allan S, editor. The Routledge Companion to news and journalism. London: Routledge; 2012. p. 637-647.

32. Entman RM. Framing: toward clarification of a fractured paradigm. J Commun. 1993;43:51-8.

33. Matthes J, Kohring M. The content analysis of media frames: toward improving reliability and validity. J Commun. 2008;58:258-79.

34. Dunwoody S. Scientists, journalists, and the meaning of uncertainty. In: Friedman S Dunwoody S, Rogers $\mathrm{CL}$, organizers. Communicating uncertainty: media coverage of new and controversial science. Mahwah: Lawrence Erlbaum; 1999. p. 59-80.

35. McCombs M, Ghanem D. The convergence of agenda setting and framing. In: Reese S, Gandy O, Grant A. organizers. Framing public life: perspectives on media and our understanding of the social world. New York: Rouledge; 2001. p. 47-70.

36. Golan G. The second-level agenda building function of the Xinhua News Agency: examining the role of government-sponsored news in mediated public diplomacy. Jornalism Pract. 2016;10(6): 744-62.

37. Baran S, Davis D. Mass communication theory: foundations, ferment and future. Boston: Wadsworth Cengage Learning; 2009.

38. Salwen M. Effect of accumulation of coverage on issues salience in agenda setting. Journalism Q. 1988;65(3):100-30.

39. Davies S, Halpern M, Horst M, et al. Science stories as culture: experience, identity, narrative and emotion in public communication of science. J Sci Commun [Internet]. 2019 [cited 2020 Oct 15];18(05):[about 17 p.]. Available from: https://jcom.sissa.it/sites/default/files/documents/ JCOM 18052019 A01.pdf.

40. Veneu F, Amorim LH, Massarani L. Science journalism in Latin America: how the scientific information from a scientific source is accommodated when it is transformed into a journalistic story. Sci Commun. $2008 ; 7(1): 1-9$. 
41. YoonY. Examining journalists' perceptions and news coverage of stem cell and cloning organizations. Journalism Mass Commun Q. 2005;82(2):281-300.

42. Massarani L, Rocha M, Pedersoli C, et al. Aproximaciones a la investigación en divulgación de la ciencia en América Latina a partir de sus artículos académicos Red de Popularización de la Ciencia y la Tecnología en América Latina y el Caribe (RedPOP), 2017 [Internet]. Rio de Janeiro: Casa de Oswaldo Cruz; 2017 [citado em 2020 out. 15]. Disponível em: https://www.researchgate.net/profile/Mariana Rocha4/publication/319165852.

43. Massarani L. Developing world and science communication research. J Sci Commun. 2013;12 (1):45-68.

44. Massarani L. Voices from other lands. Public Underst Sci. 2015;24(1):2-5.

45. Nguyen A, Tran M. Science journalism for development in the global south: a systematic literature review of issues and challenges. Public Underst Sci. 2019;28(8):973-90.

46. Elliott R. The medialization of regenerative medicine: frames and metaphors in uk news stories. In: Rödder S, Franzen M, Weingart P, editors. The sciences' media connection: public communication and its repercussions. Dordrecht: Springer; 2012. p. 87-105. (Sociology of the Sciences Yearbook; Vol. 28).

47. Amarasekara I, Grant W. Exploring the YouTube science communication gender gap: a sentiment analysis. Public Underst Sci. 2019;28(1):68-84.

48. Vicsek L. Costs and benefits of SCR and treatments: media presentation and audience understanding in Hungary. Sci Commun. 2011;33(3):309-40.

49. Barbosa A, Malik A. Desafios na organização de parcerias público-privadas em saúde no Brasil. Análise de projetos estruturados entre janeiro de 2010 e março de 2014. Rev Adm Púb. 2015;49(5):1143-65.

50. Acero L. Regulação internacional e governança na medicina regenerativa: trajetórias do Reino Unido e a União Europeia e repercussões para a saúde coletiva global. OIKOS. 2019;18(2):82-95. 